\title{
Underweight and Its Correlation with the Risk of Malaria in Children Under Five at Sanggeng Health Center, West Papua
}

\author{
Nurtiyani Rahayu'), Dwi Iryani2), Priscilla Jessica Pihahey²) \\ 1) Midwifery student, School of Health Polytechnics Sorong \\ 2) School of Health Polytechnics Sorong
}

\begin{abstract}
Background: Malaria is an infectious disease caused by the Plasmodium parasite that reproduces in human blood cells. Malaria can affect adults, children, toddlers, and infants. This study aimed to determine the relationship between the nutritional status of children under five and the risk of malaria infection.

Subjects and Method: A cross-sectional study was carried in Sanggeng Health Centre, West Papua in Mei 2021. A sample of 71 children under five was selected for this study by fixed-disease sampling divided into 34 children under five with control 37 children under five were not sick with malaria by having body mass index data. The dependent variable was malaria. The independent variable was nutritional status. The data were analyzed by multiple logistic regression.

Results: A total of 23 children under five $(67,65 \%)$ with underweight nutritional status experienced malaria. underweight in children under five are three times more likely to have malaria than children with ideal body weight and it was statistically significant $(\mathrm{b}=3.06 ; 95 \% \mathrm{CI}=1.15$ to $8.11 ; \mathrm{p}=0.024)$.

Conclusion: Underweight in children under five is positively associated with the risk of malaria.
\end{abstract}

Keywords: nutritional status, underweight, malaria, children under five

\section{Correspondence:}

Nurtiani Rahayu. Midwifery student, School of Health Polytechnics Sorong. Jl. Slamet Riyadi Kampung Ambon Atas. Email: nurtiani56@gmail.co. Mobile: +6281245957527 